\title{
The Influence of Emotion and Gender on Work Efficiency in Hazy Weather
}

\author{
Yaozhong Liu, Min Liu, Kai Yu \\ School of Management, Jinan University, Guangzhou, China \\ Email: liumin0703@126.com
}

Received 31 March 2015; accepted 4 May 2015; published 8 May 2015

Copyright (C) 2015 by authors and Scientific Research Publishing Inc.

This work is licensed under the Creative Commons Attribution International License (CC BY). http://creativecommons.org/licenses/by/4.0/

(c) () Open Access

\begin{abstract}
In recent years, the eastern part of China has suffered numerous large-scale continuous fog and haze, which seriously impact people's production and life. In present research, a combination method of questionnaire and experiment is used to discuss whether the hazy weather could influence the emotion and if there are any impacts on the work efficiency. 2 (gender) $\times 3$ (emotional type: positive, neutral and negative) completely randomized design is used and the reaction time (RT) is analyzed. The results show that 1 ) hazy weather truly induces the negative emotion, e.g. depression and anxiety; 2) the interaction effect of emotion and gender is significant; the RT of females is significantly longer than males' in negative emotion condition; for females, $R T$ in negative emotion condition is significantly longer than that in positive and neutral emotion condition, which shows that the hazy weather would lead some inefficiency.
\end{abstract}

\section{Keywords}

Negative Emotion, Work Efficiency, Hazy Weather, Gender, Working Memory

\section{Introduction}

Weather is widely believed to influence the individual's mood [1]. World Health Organization's (WHO) data showed: "El Nino" phenomenon during 1982-1983 made about 10 million people suffer from depression, a significant increase in the incidence of mental illness and traffic accidents. Some studies have also found that seasonal affective disorders (SAD) were mainly occurred in the spring [2]. According to some physiological data, in sunny day when the sunshine is sufficient, the body's pineal gland inhibited by the light decreases the secretion of hormones, while the secretion of thyroxine and adrenaline rises; in rainy day, the situation is reversed. Thyroxine and adrenaline can promote cell metabolism, increase oxygen consumption, and stimulate tissue growth and differentiation. In hazy day, it is dim, which is bound to make the pineal gland physiological 
changes. It is apparent that hazy weather and people's emotion are closely related.

Emotion is often described to be the response to the important events which are produced in an internal or external situation. People always have the same response to the same event. The duration of emotion is usual short, with a group of co-ordinated response including language, physiological, behavioral and neural mechanisms. Emotion has often been conceptualized within a cirumlplex structure of affect. In this structure, the dimensions of valence (unpleasantness vs. pleasantness) and arousal (low vs. high) can be distinguished [3]. Negative emotions often include stress, anger, depression, anxiety, sadness, fatigue, etc.

There is a gender difference in emotional experience. Studies have showed that female can experience the emotion more frequently than male as well as the intensity [4]. Grossman and Wood have selected five different emotions (including fear, joy, sadness, anger and love) to be compared [5]. The results were consistent to the conclusion above. On the basis of previous studies, the present study supposes that the emotion experience induced by the hazy weather has a gender difference.

Studies have shown that emotional state would influence the cognitive processes [6], and the male's response to negative emotions tends to be more rational [7]. Eysenck and Calvo proposed the "processing efficacy theory". They argued that the resources of individual working memory system were limited; the negative emotion (e.g. anxiety) would occupy part of the working memory resources, so that the resources for individual cognitive operations were corresponding reduction [8]. In some organizations which require mental activities, job performance depends on the individual's own cognitive capacity. If the cognitive overloads, it maybe lead to lower productivity. At a specific time or during short time, individual characteristic is relatively stable. But in the course of continuous operation, individual characteristic (such as mood) is changing; cognitive load condition would also be different.

The study of emotion measurement has been very mature in the past 20 years, including self-report, physiological measurements, EEG, neuro image, and behavior measurement. In present study, self-report measurement is used. Studies have shown that both task and domain knowledge are essential components of problem-solving accuracy; however, a variety of other variables were related to it, e.g. working memory capacity [9]. In real situations, problem-solving accuracy is essential to work efficiency. Thus, in our laboratory, the working memory is tested to forecast the work efficiency. The better the working memory capacity is (that is the lower the reaction times are), the higher the working efficiency is. Studies have shown that the movie clips which use a combination of dynamic visual and sound are considered to be the most effective method to induce emotions. Fang Li, Shaohong Zhu, and Xuejun Bai (2008) argued that when the positive emotion was induced, subjects' response in 3 min was significantly higher than baseline levels', while negative was for $5 \mathrm{~min}$, so the present experiment was controlled in 5 min.

\section{Methods}

\subsection{Participants}

Thirty students from Jinan University (15 males and 15 females) for lab experiment. The participants were aged 20 to 25 years old. 164 valid questionnaires were from all over the country (89 male, 75 female). The participants were aged 18 to 40 years old. 50 people were from Qingdao, 39 people from Jinan, 13 people from Zibo, 8 people from Beijing, and the remaining subjects were from Beijing, Changsha, Changde, Binzhou, Dalian, Dongying, Foshan, Harbin, Hefei, Henan, Heze, Jining, Linyi, Nanjing, Shanghai, Tai’an, Weifang, Xuzhou, Wuhan and other cities.

\subsection{Research Design}

The experiment had a $2 \times 3$ two factors completely randomized design, with one factor referring to gender (male vs. female) and another factor referring to emotional type (negative vs. neutral vs. positive emotion). Both of them are between-subject variable. The dependent variable was the reaction time (RT) in Recognition Task.

\subsection{Research Tools}

The Multiple Affect Adjective Check List (MAACL). MAACL includes hostile checklist (H), depression checklist (D) and anxiety checklist (A), of which $H$ checklist contains 19 words (11 positive words vs. 8 negative words), D checklist contains 25 words (6 positive words vs. 19 negative words), A checklist contains 16 words (6 
positive words vs. 10 negative words). Participants were asked to choose the adjectives which was reflect the feels in hazy weather. Negative words chosen scored a point, positive words not chosen scored a point, which represents the negative emotions. The Reliability of $\mathrm{H}$ checklist is 0.864 , D checklist is 0.871 , A checklist is 0.750 , which have reached the metrology requirements for clinical evaluation and experimental research.

Movie clips: "Modern Times" to induce positive emotion; "My brothers and sisters" to induce negative emotion "Penguins" to induce neutral emotion. All of them are controlled in $5 \mathrm{~min}$.

\subsection{Research Procedure}

The present research was divided into two sections. First, MAACL, mainly through the network platform, was used to collect the data of emotion for hazy weather. Secondly, participants took part in the lab experiment.

Experiment was operated by computer and experimental program prepared by E prime 2.0. After beginning, participants would watch a movie which was about 5 min first, then the experiment was divided into two phases. The first phase is Memorizing Task (Figure 1), the second phase is Recognition Task (Figure 2). “+” would appear to prompt the task. In Memorizing Task, 20 neutral words would be presented for 2 s. Participants needn’t give a key reaction, they need memorize all the words as much as possible; In Recognition Task, 40 neutral words which contained 20 words in Memory Task would be presented for 4 s/each. If the word appeared in both tasks, participants should press "F"; if not, press “J”. Participants were also asked to press the key as accurately and quickly as possible.

\section{Results}

\subsection{Gender Difference of Emotion in Hazy Weather}

SPSS13.0 was used to do One-Way ANOVA test for the data in Table 1. The results show that in hazy weather, females $(M=10.11 \pm 3.58)$ produced a more emotional feelings of depression than males $(M=6.82 \pm 3.39), F$ $(1,162)=8.369, p<0.01$; what's more, females' score of anxiety $(M=8.23 \pm 2.46)$ also higher than males (M $=6.82 \pm 2.59), F(1,162)=12.586, p<0.01$; while on the score of hostility, males $(M=11.07 \pm 2.28)$ and females $(M=11.68 \pm 1.95)$ didn't have difference, $F(1,162)=3.344, p>0.05$.

\subsection{Effect of Emotion and Gender on Working Memory}

Exclude the data of which the accuracy rate was less than $80 \%$. SPSS13.0 was used to do Two-Way ANOVA test for the data in Table 2.

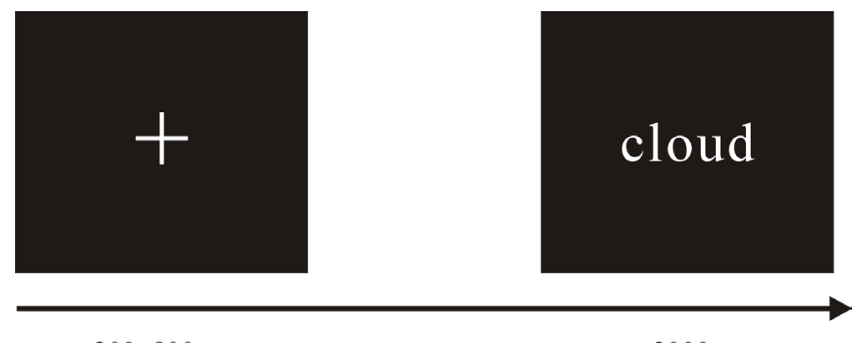

$200 \sim 800 \mathrm{~ms}$

$2000 \mathrm{~ms}$

Figure 1. The memorizing task.
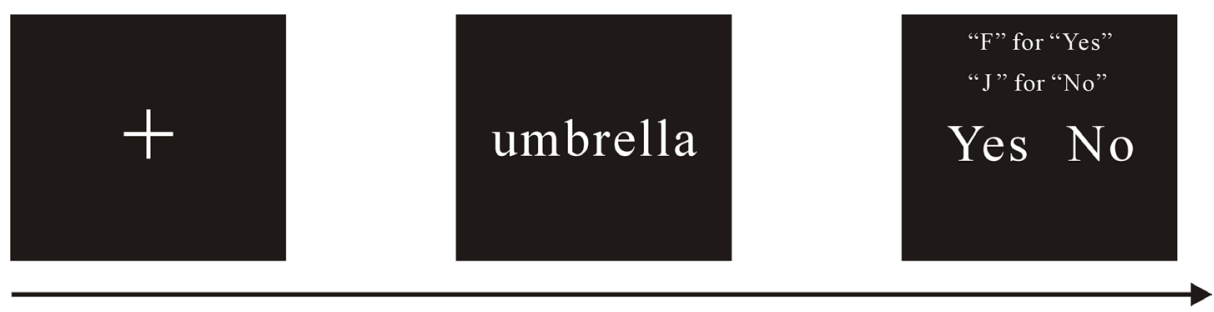

$200 \sim 800 \mathrm{~ms}$

$2000 \mathrm{~ms}$

$4000 \mathrm{~ms}$

Figure 2. The recognition task. 
Table 1. Average and standard deviation of scores in different group on MAACL.

\begin{tabular}{cccccc}
\hline & \multicolumn{2}{c}{ Female } & \multicolumn{2}{c}{ Male } \\
\cline { 2 - 5 } Emotional type & Mean & SD. & Mean & SD. \\
\hline Hostility & 11.68 & 1.95 & 11.0 & 2.28 \\
Depression & 10.11 & 3.58 & 8.52 & 3.39 \\
Anxiety & 8.23 & 2.46 & 6.82 & 2.59 \\
\hline
\end{tabular}

Table 2. Average and standard deviation of RTs in different group.

\begin{tabular}{ccccc}
\hline \multirow{2}{*}{ Emotional type } & \multicolumn{2}{c}{ Female } & \multicolumn{2}{c}{ Male } \\
\cline { 2 - 5 } & Mean & SD. & Mean & SD. \\
\hline Positive emotion & 973.96 & 93.49 & 823.59 & 65.54 \\
Neutral emotion & 1180.06 & 131.17 & 942.49 & 107.83 \\
Negative emotion & 1868.88 & 681.48 & 997.97 & 194.08 \\
\hline
\end{tabular}

ANOVA revealed the main effect of emotion $\left(F(2,24)=8.287, p<0.01, \eta^{2}=0.408\right)$ and gender $(F(1,24)=$ 14.566, $\left.p<0.01, \eta^{2}=0.378\right)$ were both significant. Post Hoc test revealed the RT of females $(M=1340.96 \pm$ 544.97) were significant longer than males $(M=921.35 \pm 144.847)$. It also revealed that the RT in negative emotion condition $(M=1433.42 \pm 658.67)$ was significantly longer than that in positive $(p=0.001)$ and neutral emotion condition ( $p=0.011)$; while there were no significant difference between the group of positive $(M=$ $898.77 \pm 109.88)$ and neutral emotion $(M=1061.28 \pm 168.80)$.

The results showed that the interaction effect of emotion and gender is significant $(F(2,24)=4.265, p<0.05$, $\eta^{2}=0.262$ ) as show in Figure 3, indicating that both the emotion and gender influence the working memory. Simple effect test revealed that the effect of gender is significant in the group of negative emotion, indicating that the RT of females $(M=1868.88 \pm 681.48)$ was significantly longer than that of male $(M=997.97 \pm 194.08)$, $F(1,24)=20.916, p<0.01, \eta^{2}=0.466$; while RTs in positive emotion $\left(F(1,24)=1.556, p=0.224, \eta^{2}=0.061\right)$ and neutral emotion condition $\left(F(1,24)=0.623, p=0.438, \eta^{2}=0.025\right)$ had no gender difference. What's more, in the group of females, RT in negative emotion condition $(M=1868.88 \pm 681.48)$ was significantly longer than that in positive $(M=973.96 \pm 93.49, p<0.01)$ and neutral emotion condition $(M=1180.06 \pm 131.17, p<0.01)$; while in the group of males, there were no significant differences among three types of emotion.

\section{Discussion}

Analysis of the Multiple Affect Adjective Check List (MAACL) showed that the hazy weather could evoke the negative emotions in varying degrees. Feeling of depression and anxiety in females was significantly stronger than males, which is consistent with the results of previous research. Wood and Rhodes (1992) believes that gender differences in emotional experience came from the differences of the roles that males and females served in society. Females have a greater opportunity to link with the emotion-related skills and to develop the beliefs and values about emotion sensitivity and emotion expression [10]. Grossman et al.'s study has also found that female could experience more deeply than males.

Analysis of experimental data showed that the individual reaction time (RT) under negative emotion is significantly lower than that under positive and neutral emotion, indicating that negative emotions could truly interfere with working memory. According to "the processing efficiency theory", the brain operation mechanism for negative emotions and working memory is same. When the negative emotion was evoked, the resources occupied by working memory reduced, which made the resources allocated to memorizing task were insufficient. Thus, in the recognition task, the RT was longer. Because the emotional perception of females is stronger than males, the resources that process negative emotions are more occupied, leading to RT in the recognition task is longer than males.

In hazy weather, individual's emotions are affected, which will inevitably affect people's production and life. 


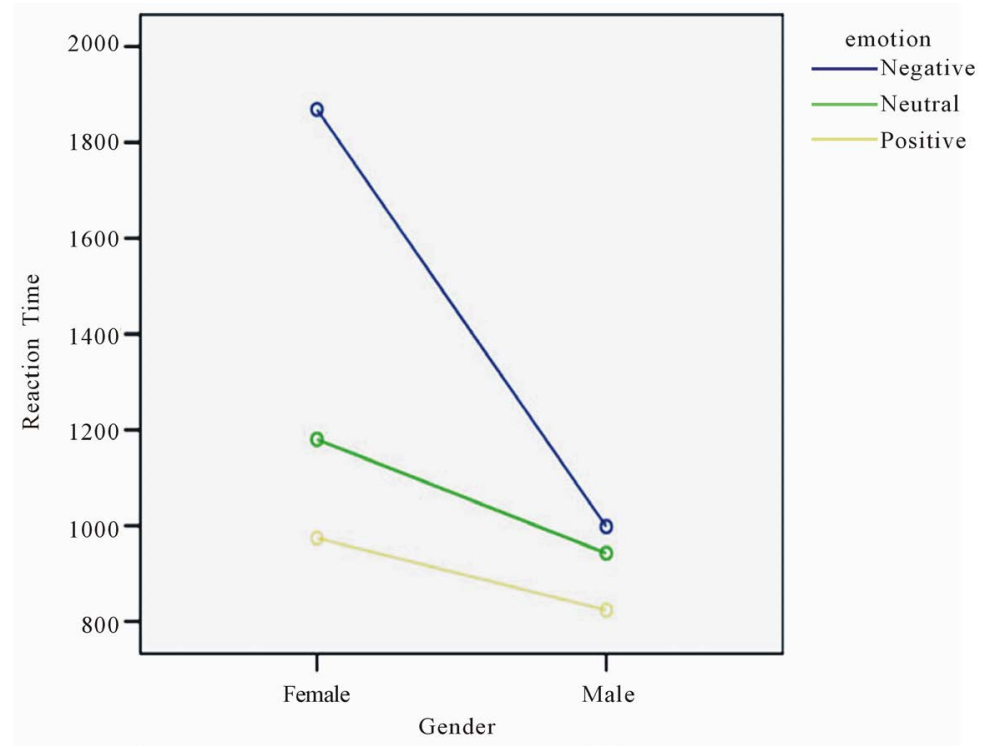

Figure 3. The interaction effects of emotion and gender on working memory.

In addition, fog and haze can harm the human body. Studies abroad showed that the toxic particulate matter in air is an important cause of cardiovascular disease. What's more, the results of present study indicated that bad weather was one of the reasons that reduced the work efficiency. In the course of organizations' long-term development, if employees are in a long-term negative emotional state, it will inevitably impact the production. Thus, the emotional management of employees plays a very important role.

In present study, we controlled the demographic factors e.g. age and working experience, and have obtained some meaningful discoveries. There are some limitations of the study to be discussed in the future. First, as to participants, sampling range of 30 may be a little narrow. Second, besides word memory-recognition task, the future studies can choose the new task to measure the working memory. Additionally, new variables to forecast the work efficiency in organizations are essential to be studied in the future.

\section{Conclusion}

Hazy weather can induce negative emotional perception, which shows gender differences: the perception of females is stronger than that of males; negative emotions and gender interact the working memory: RT of females is significantly longer than that of males in the group of negative emotions, and RT of females in negative emotion condition is longer than that in positive and neutral emotion condition. In the rest of conditions, there is no significant difference being found.

\section{References}

[1] Denissen, J.J., Butalid, L., Penke, L. and Van Aken, M.A. (2008) The Effects of Weather on Daily Mood: A Multilevel Approach. Emotion, 8, 662. http://dx.doi.org/10.1037/a0013497

[2] Young, M.A., Meaden, P.M., Fogg, L.F., Cherin, E.A. and Eastman, C.I. (1997) Which Environmental Variables Are Related to the Onset of Seasonal Affective Disorder? Journal of Abnormal Psychology, 106, 554-562. http://dx.doi.org/10.1037/0021-843X.106.4.554

[3] Feldman Barrett, L.A. (1995) Valence Focus and Arousal Focus: Individual Differences in the Structure of Affective Experience. Journal of Personality and Social Psychology, 69, 153-166. http://dx.doi.org/10.1037/0022-3514.69.1.153

[4] Li, F. and Lu, S.H. (2014) Gender Differences in Emotional Experience and Its Causes. Social Psychological Science, 2, 40-43.

[5] Grossman, M. and Wood, W. (1993) Sex Differences in Intensity of Emotional Experience: A Social Role Interpretation. Journal of Personality and Social Psychology, 65, 1010-1022. http://dx.doi.org/10.1037/0022-3514.65.5.1010

[6] Storbeck, J., Davidson, N.A., Dahl, C.F., Blass, S. and Yung, E. (2015) Emotion, Working Memory Task Demands 
and Individual Differences Predict Behavior, Cognitive Effort and Negative Affect. Cognition and Emotion, 29, 95117. http://dx.doi.org/10.1080/02699931.2014.904222

[7] Yang, Z., Dubé, L. and Ma, Z. (2015) Males’ Responses to Negative-Emotion Advertising Appeals: Effects of Gender Role Socialization and Disposition toward Rational Thinking. Assessing the Different Roles of Marketing Theory and Practice in the Jaws of Economic Uncertainty, Springer International Publishing, 84. http://dx.doi.org/10.1007/978-3-319-11845-1_32

[8] Eysenck, M. and Calvo, M. (1992) Anxiety and Performance: The Processing Efficiency Theory. Cognition and Emotion, 6, 409-434. http://dx.doi.org/10.1080/02699939208409696

[9] Seitz, K. and Schumann-Hengsteler, R. (2000) Mental Multiplication and Working Memory. European Journal of Cognitive Psychology, 12, 552-570. http://dx.doi.org/10.1080/095414400750050231

[10] Desteno, D., Bartllett, M.Y., Braveman, J. and Salovey, P. (2002) Sex Differences in Jealousy: Evolutionary Mechanism or Artifact of Measurement? Journal of Personality and Social Psychology, 83, 1103-1116. http://dx.doi.org/10.1037/0022-3514.83.5.1103 